\title{
LOS GOBIERNOS LOCALES, LOS CARGOS CIVILES Y LOS CARGOS RELIGIOSOS EN LAS RECIENTES ETNOGRAFÍAS EN EL ESTADO DE OAXACA, MÉXICO
}

\author{
LOCAL GOVERNMENTS, CIVIL SERVANTS AND RELIGIOUS OFFICIALS IN \\ RECENT ETHNOGRAPHIC STUDIES IN THE STATE OF OAXACA, MEXICO
}

\author{
Hilario Topete Lara*
}

\begin{abstract}
Los sistemas de cargos son uno de los temas predilectos de la antropología política en Mesoamérica, pero también uno de los temas más superficialmente abordados; por ello, el presente ensayo propone un recorrido en torno de sus características y en el que enfatizo que entre estas se encuentra la gratuidad del servicio y el apego a normas comunitarias; de allí lo que ocurre en los últimos años en algunas localidades mixtecas del Estado de Oaxaca, en México.
\end{abstract}

Palabras claves: Sistemas de cargos, gobiernos locales, APPO, Oaxaca, Mixteca región.

Cargo Systems is one of the favorite themes of political anthropology in Mesoamerica, but also one of the topics addressed superficially; therefore, this article proposes a route for its characteristics and those who have emphasized the unpaid service and adherence to local regulations. This helps explain the events in some places Mixtec in Oaxaca, Mexico.

Key words: Cargo systems, local gobernment, APPO, Oaxaca, Mixteca región.

En la década de los cincuenta del siglo XX, en su Formas de gobierno indígena, Gonzalo Aguirre Beltrán (1983) arrojó al mundo antropológico, inmisericordemente, un concepto: gobierno local. Pronto adquirió carta de naturalización y se convirtió, junto con el de comunidad, en uno de los términos predilectos de la banda antropológica; sin embargo, a ambos les ocurrió lo mismo: se les utilizó sin la debida reflexión y, carente de contenido, como categoría operativa, podría significar cualquier cosa. No es mi intención discutir ambos términos, pero sí se hace indispensable que, si he de referirme a los gobiernos locales, aclare qué entiendo por ellos. Voy a hacer, sin embargo, un deslinde necesario: el que nos evite homologar a sistemas de cargos o cualquier forma de organización para el ceremonial de gobierno local.

Hace ocho décadas, Sol Tax (1937), al estudiar los municipios en las tierras altas de Guatemala, encontró que las autoridades civiles y las religiosas se encontraban sólidamente enlazadas, alternadas y dispuestas en un escalafón, entre otras peculiaridades. A esto llamó "municipio indio". Sin proponérselo, quizá, estaba trazando la vía por medio de la cual algunos investigadores llegarían al sistema de cargos, como propusieron F. Cancian (1973) y L. Korsbaek (1996); o quizá se refería a lo que más tarde P. Carrasco (1990) llamaría jerarquía políticoreligiosa, o probablemente se trataba del gobierno local de G. Aguirre Beltrán. Lo único seguro es que había iniciado un camino que podría llevar de forma rápida a una contagiosa confusión a futuros investigadores, como ha ocurrido.

Así, el sistema de cargos de L. Korsbaek o la jerarquía político-religiosa de P. Carrasco fue conocida por sus características más relevantes: cargos dispuestos de manera jerárquica en un número determinado, y accesibles a todos los miembros de la comunidad; rotabilidad entre los miembros de la comunidad; duración en el cargo por poco tiempo, generalmente un año; gratuidad del servicio y/o -en su caso- financiamiento de las obligaciones mediante trabajo, insumo y dinero, según fuese el caso; entrega de prestigio de la comunidad como recompensa a quien ejerciese cargos; alternabilidad de los cargos mediante escalafón; constitución de "principales", "pasados", "tatás", "ancianos" o "caracterizados" al término del recorrido por todos los cargos.

Sistema de cargos, entre descripciones sin comparaciones previas, y sin la suficiente literatura

* Escuela Nacional de Antropología e Historia, Instituto Nacional de Antropología e Historia, México. Correo electrónico: topetelarah@yahoo.com 
y reflexión sobre los cargos, pasó a ser -en muchos casos-sinónimo de gobierno local, en una mayúscula coincidencia con el "típico sistema de cargos" de L. Korsbaek y muchos de sus seguidores, algunos de los cuales no solo extendieron el concepto para abarcar cada forma de autoridad, sino para llevarlo a cualquier latitud de esa superárea que Kirchhoff llamó Mesoamérica (algunos mas allá); esto, a pesar de que el danés se encargó de aclarar, originalmente, que la categoría solo podría ser válida en la etnorregión de cuyo estudio había surgido ella, aunque quizá en algunas otras etnorregiones también fuese aplicable, propuso más tarde. Luego, fuera de allí, aunque no existiese el "típico sistema de cargos" en algunas localidades indígenas o con una pronunciada matriz prehispánica, podría haber alguna forma de gobierno local. Aguirre Beltrán desde décadas antes se había inclinado hacia esa idea.

Años más tarde escribí dos ensayos, uno de los cuales llevaba una tipología incorporada (Topete, 2005b). La intención era provocar a la comunidad "cargológica" para pensar en la especificidad de los conceptos "cargo", "cargos religiosos", "sistema de cargos", "sistema de cargos religiosos", "sistema de cargos cívico-religiosos", "cofradías", "puesto" y, entre otros, "organización social para el ceremonial" (Topete 2005a). A esa aproximación siguió una más, en la que "cargo", independientemente de que fuese de carácter religioso o cívico, quedaba distanciado de puesto debido a la gratuidad del servicio a la comunidad $^{1}$ por un tiempo perentorio y sujeto a normas locales; la gratuidad -proponía- presupone el financiamiento (patrocinio) del cargo, toda vez que tanto el patrocinio como el trabajo brindado en la administración pública o en la organización de la fiesta no le son retribuidos al carguero; $y$, por último, el ejercicio de un cargo, en tanto que es reconocido por la comunidad, proporciona membresía e identidad. Puesto, en cambio, era concebido como una función retribuida económicamente para un servicio a favor de la comunidad y sujeta a normas extralocales (constitucionales, por ejemplo).

En esos trabajos proponía que distanciar entre cargos religiosos y civiles no significaba que carecieran de algún género de articulación entre sí, proviniera esta de algún cargo dispuesto específicamente para ello simple y difusa, o enmascaradamente a veces, en las normas locales. Así, existen registros etnográficos en los cuales las autoridades civiles aparecen como coadyuvantes en el cumplimiento de algún cargo o fiesta religiosa con auxilio financiero o de infraestructura, sin que ello indique la existencia de un sistema de cargos cívico-religioso, un sistema político-religioso o al menos un sistema de cargos (religioso o no). En efecto, allí donde solo existe una mayordomía con patrocinio individual ${ }^{2}$, aunque las autoridades civiles les franqueen el paso en las procesiones o vigilen el tránsito durante la fiesta, no existe un sistema de cargos, ni de los dos enunciados, ni de carácter religioso siquiera, proponía ${ }^{3}$. En cualquiera de los tipos y circunstancias los sistemas de cargos (o los cargos que no constituyen un sistema) y las autoridades civiles -agrarias incluso, allí donde es el caso-, solas o en coadyuvancia, quedarían englobadas en la extensión (infra) de la categoría organización social para el ceremonial. Había propuesto, pues, relaciones entre familias de conceptos para indicar su distancia y proximidad (comprensión y extensión $)^{4}$, partiendo desde el de mayor (organización social para el ceremonial) hasta el de menor generalidad (cargo) y a este lo había distanciado mediante la diferencia específica en religiosos y civiles (infra) ${ }^{5}$.

Apenas iniciaba a pensar el asunto, en la literatura cargológica me reapareció el concepto de gobierno local, y hubo menester dedicarle algo de atención. Para evitarme confusiones, aduje que por gobierno local entiendo la forma de organización del poder y las autoridades (con la finalidad de emprender proyectos colectivos y atender los asuntos internos y aquellos que inevitablemente se relacionan con la sociedad mayor que los contiene), de acuerdo con un sistema normativo donde tienen un peso considerable las normas autogeneradas, y un proyecto comunitario, independientemente de la índole que ambos posean; por ende, en un gobierno local pueden ser incorporadas tanto las autoridades político-administrativas del ayuntamiento, las autoridades judiciales, las autoridades agrarias, las autoridades de la organización ceremonial religiosa (sistema de cargos religiosos, mayordomías, etc.) o cualquiera combinación de ellas. Consecuentemente, el gobierno local puede atender, entre otros $-\mathrm{O}$ algunos de los siguientes- asuntos:

a) al ciclo ceremonial, es decir, fiestas patronales, de mitades y barriales, oficios religiosos y, eventualmente, de ciertas ceremonias vinculadas con el ciclo de vida como enlaces matrimoniales, apadrinamientos, propiciamientos y peticiones (de lluvia, buenas cosechas, alejamiento de plagas u otros), danzas, representaciones, etc. 
b) al ciclo agrícola y a las cuestiones de tenencia de la tierra, es decir, a los problemas de linderos, organización de la preparación del terreno y la cosecha, así como controversias de usufructo; asimismo, por medio de él se realizan las gestiones de todo tipo ante las autoridades agrarias federales y locales en materia agraria.

c) a la impartición de justicia, mediación en -y atención de-conflictos no judiciales más conforme con los sistemas normativos comunitarios que con el derecho positivo escrito.

d) a la administración de los servicios igual que la reglamentación local (estatal) del Artículo $115^{\circ}$ Constitucional.

e) la organización de los trabajos colectivos para obras de uso común.

Un gobierno con tales características presupone que la comunidad goza de algún grado de autonomía -que no de independencia- y de soberanía sobre asuntos que a ella interesan, independientemente de lo que el derecho positivo escrito prescriba; además, atiende de manera menos fragmentaria y más integral los asuntos que a la comunidad competen; asimismo, y parafraseando libremente una idea de Fernando Cámara Barbachano (2006), tiene más fuerza centrípeta $\mathrm{y}$, consecuentemente, es más cohesionante, aglutinante, y al expresarlo de ese modo de ninguna manera pienso en la comunidad campesina corporativa y cerrada de la que nos habló E. Wolf (1981). Un gobierno local con esas características no marca tajantemente la distancia entre lo público y lo privado, y el sistema normativo a que atiende y hace respetar se vincula más con cierta noción de colectividad que hace posible, entre otras cosas:

a) la pervivencia del tequio o faenas colectivas, para obras de beneficio común (construcción de iglesias, caminos, escuelas, remozamiento de sitios de recreación, etcétera).

b) la solución de conflictos según formas socioculturales específicas (comunitarias) que privilegian a la comunidad, a la mitad, al barrio, a la familia, es decir, al ente colectivo antes que al individuo, sin que el individuo sea difuminado; eventualmente, la mediación en controversias de macoa $^{6}$ o manos-vueltas, etc. En tales circunstancias, la inserción de los individuos en redes parentales hace más expeditas las negociaciones.

c) el acceso y control de recursos conforme con las decisiones comunitarias más o menos consensuadas; consecuentemente el peso de las asambleas es determinante para dirimir ideas e implementar lo establecido en acuerdos.

d) la permanencia de cuerpos de ancianos, probados en el servicio comunitario, como asesores en asuntos de ceremonias, etiquetas, vínculos con el exterior, ciclos agrícolas, tradición oral, etc.

\section{Los gobiernos locales en los tiempos de la globalización}

Los gobiernos locales, al menos los que conozco, pese a lo que se supone, no fueron producto de una política diseñada por el Estado español, sino:

a) de las adaptaciones hechas del sistema de autoridades civiles y religiosas coloniales y de la fusión de autoridades de un tipo y de otro, ocasionalmente asociadas a las fluctuaciones demográficas y, en algunos casos, debido a que las autoridades religiosas organizaron la vida civil;

b) de la creatividad de comunidades que inevitablemente tenían indígenas en el traspatio o que tuvieron contacto con instituciones indígenas sólidas y eficientes;

c) de la complicidad de las autoridades religiosas y civiles que tenían que dar cuenta de reducciones, congregaciones, repúblicas de indios y comunidades indígenas ante el Estado español;

d) del aislamiento que los colocó en posibilidades de ejercicios autonómicos frente a los vacíos que el Estado dejaba en materia de seguridad, autoridad y justicia; y, entre otras más,

e) de los recursos que quedaron bajo control de las propias comunidades.

Por ende, los gobiernos locales funcionaron bien hasta que el Estado se impuso tener control de ellos generando, cuando esto ocurría, crisis que obligaron a resistencias, negociaciones, refuncionalizaciones, creaciones, etc., como fueron, en su momento, las etapas posteriores a: a) la época de las Reformas borbónicas; b) la época de la Reforma; c) la posrevolución, y, por último, d) la globalización. En suma, pocos momentos de respiro pero muchos para las reconfiguraciones.

Estamos, en la época presente, en una nueva etapa de impasse para los gobiernos locales, muy diferente a las que le antecedieron. Y, aunque sea solo parcialmente cierto, diré que tuvo en México un crescendo en la época de los ochenta, y en las modificaciones del artículo $27^{\circ}$ constitucional, uno 
de sus momentos culminantes. En efecto, lo que ocurrió es que Carlos Salinas de Gortari cerró un ciclo al concretar un viejo proyecto liberal: hacer a los ejidatarios, al menos por el espíritu jurídico de la reforma, propietarios privados; se trata, ni más ni menos, que el sueño de la segunda mitad del siglo XIX expresado en las leyes de reforma elevadas a categoría de ley según la Constitución del 57, pero elevado a su máxima potencia con el proyecto neoliberal que adquirió auge en la administración del antecitado Presidente de la República.

Bajo esta idea, lo que tenemos es que en México la culminación tardía de un capítulo del proyecto liberal coincidió con la apertura al neoliberalismo; por ende, ha pasado en México un poco de lo ocurrido en la Rusia de principios del siglo XX: no bien se había exterminado el feudalismo cuando se abrían las puertas al capitalismo en cuyo interior, a la vez, se incubaba la revolución socialista, esto es, un encabalgamiento de fases. También, bajo esa idea, debo recordar que el combate frontal contra los gobiernos locales no vino solo desde la economía, porque un gobierno local no requiere forzosamente de formas comunales o ejidales, sino de formas de entender las cosas públicas en general; en efecto, el embate llegó desde el mismo constituyente de 1957 que se había lanzado frontalmente contra las corporaciones, y ese embate simplemente cambió de rostro cuando desde el constituyente de 1917 estableció el municipio libre; otro duro golpe provino, en cambio, de la imposición del municipio a la mexicana.

A diferencia de la forma de entender el municipio libre en Europa, donde en algunas naciones unos cuantos de ellos se federaron para atender asuntos comunes, como ocurrió por ejemplo, aunque con la distancia debida de por medio, entre los cantones suizos, en el México del siglo XIX la génesis, la estructura y el funcionamiento -en términos generales- fueron diseño y dictado heterónomos y se enlazó a las circunscripciones de tal forma que pasaron a depender directamente de una voluntad superior, "El Estado", "La Nación". La exigencia del Estado (mejor: gobierno) por la instauración del municipio y los ayuntamientos fue ese primer gran golpe-maestro-contra los gobiernos locales; el impacto mayor lo recibieron las localidades con una marcada raigambre indígena. La imposición del municipio empezó cristalizarse más rápidamente cuando, para exigir el cumplimiento de la ley, el gobierno estuvo dispuesto a utilizar la fuerza; cuando contó con un aliado-apóstol secular llamado profesor; cuando empezó a requerir el control de toda clase de recursos para proveer de materias primas a la industria nacional e internacional; cuando se necesitó de un cuantioso capital político para imponer precios de garantía, transferir tierras, obtener votos; cuando hubo necesidad de incorporar a cualquier clase de individuo a la economía de mercado con una lógica consumista; cuando se requería de un credo ciudadano basado en la noción de una persona individual, aislada, solitaria, débil frente al Estado. Si había menester pagar por ello, esa necesidad tendría un costo menor que la factura que tenían que pagar las localidades que sucumbieran; en efecto, allí estaba el canje a cambio de algo de luz, de agua potable, de caminos y carreteras, educación, teléfono y pago a las autoridades civiles, entre otros.

El gobierno, durante todo este proceso, jugó un papel tan ambivalente como importante: mientras por un lado manifestó su "preocupación por los desprotegidos" y se cobijó con el gabán del paternalismo, establecía los precios de garantía y los salarios mínimos para subsidiar la acumulación capitalista manteniendo los insumos baratos en las ciudades, a costa del detrimento de la economía de los campesinos, el abandono del campo, la migración forzosa de los campesinos que fueron a engrosar el ejército de reserva de fuerza de trabajo en las ciudades o en el extranjero. La etapa del desarrollo estabilizador tuvo su base en esta estrategia: mientras implementaba el Sistema Alimentario Mexicano (SAM), estimulaba el proceso de distorsión económica que tendía a eliminar bosques y campos agrícolas para convertirlos en áreas de pastoreo donde criar un ganado cuya carne nunca estuvo en la canasta básica ni en los alimentos subsidiados o con tasa cero del Impuesto al Valor Agregado (IVA); mientras llevaba la educación básica hasta los últimos rincones del país para crear cuadros básicos de competencia al servicio de la burguesía evidentemente, aunque no lo declarara, aumentaba las exigencias académicas de quienes se incorporaban a la planta productiva (la licenciatura empezó a servir "para un barrido y un fregado"); mientras se implementaba el indigenismo, se imponía el Plan Nacional de Once Años con el que se establecía la obligatoriedad de una lengua nacional; mientras exaltaba el orgullo de su plurietnicidad y la diversidad de sus pueblos, desarticulaba los gobiernos locales con el régimen de partidos, ese delicioso botín que engordó tantos y tantos bolsillos 
de diputados y presidentes municipales; mientras que establecía el PROCAMPO ${ }^{7}$ y el PROCEDE ${ }^{8}$, importaba maíz de los campos agrícolas de Texas, etcétera.

Los tiempos de la globalización fueron también útiles: sirvieron para atacar el romanticismo irracional de quienes, iracundos, denunciaron el progreso manifiesto, por ejemplo, en el consumo de Coca-Cola hasta en el caserío más apartado del país, a la vez que -ese mismo progreso- puso al alcance de las manos indígenas y campesinas, la comunicación y el mundo mediante la televisión, la radiotelefonía y la internet; fueron útiles para derrumbar barreras a la asequibilidad de foros y a las resistencias etnolocales como las de México y Bolivia, por citar solo dos casos emblemáticos. Fueron útiles para saltar a la palestra y a los foros públicos exigiendo el respeto a sus derechos comunitarios, exigiendo autonomía y participación en el destino de los recursos ancestralmente administrados o custodiados como parte de un mundo más sagrado que explotable y, por ende, para una redefinición de la noción de soberanía. Los estados nacionales con frecuencia ignoraron las nuevas circunstancias, cuando no lanzaron la fuerza militar, policiaca y tribunalicia sobre las espaldas y requerimientos desde las localidades. No en balde este raro fenómeno de reclusión de las etnias y los movimientos nacionales frente a los estados como el que sostienen, entre otros, desde la primera década del siglo XXI, los wirrárika y los warijoó del occidente y del noroccidente de México, respectivamente.

Hoy, en México y en el mundo, acudimos al establecimiento de una nueva correlación de fuerzas en cuyo desarrollo ha sido cada vez más notoria la puja por los derechos étnicos y culturales con base en el Convenio 167 de la Organización Internacional del Trabajo y el eco deferente y dispar que nacionalmente ha tenido en las asambleas legislativas para incorporar el reconocimiento -limitado y eventualmente distorsionado- de los derechos étnicos, de la pluriculturalidad. Los reclamos parecen ser simples:

a) reconocimiento de $-y$ respeto a- las formas de organización social para el trabajo y para el ceremonial;

b) reconocimiento y respeto de las formas de justicia comunitariamente generadas;

c) reconocimiento y respeto de las formas de acceso y control de la tierra y los recursos naturales ancestralmente usufructuados. d) espacios de autonomía y soberanía para la producción y reproducción de su cultura.

Sin embargo, pese a la simpleza, poco o casi nada han logrado las etnias, como no hayan sido o sean, entre otros:

a) las autonomías de la costa atlántica de Nicaragua,

b) el reconocimiento de la plurietnicidad y la multiculturalidad en México, Colombia, Brasil y Guatemala, entre otros y, para no extenderme, c) el posicionamiento de las etnias amazónicas frente al Estado para intervenir en materia de aprovechamiento del destino y aprovechamiento de los recursos.

En medio de este alud de acontecimientos, en los años ochenta del siglo pasado una efervescencia del movimiento magisterial aglutinado en la Coordinadora Nacional de Trabajadores de la Educación (CNTE) se incorporaría como un ingrediente interesante en el estudio de los sistemas de cargos y los gobiernos locales. Los profesores del nivel primario y secundario, en la práctica política de su lucha por reivindicaciones salariales y por democracia en el interior del Sindicato Nacional de Trabajadores de la Educación (SNTE), terminarían haciendo alianzas con la sociedad civil. La alianza con los padres de familia devino fundamental para garantizar soporte social de su propósito; el nivel de relación pasaba del vínculo estrechamente académico y social, al político. Un buen sector del profesorado de los estados de Michoacán, Guerrero, Estado de México y Oaxaca, por citar solo cuatro entidades federativas, logró notoria presencia local en tanto que, en reciprocidad, se comprometía -en calidad de gestores- en los procesos de obtención de obras públicas y programas sociales de apoyo y desarrollo social. La lucha sindical se había convertido en el crisol de una alianza de la que iniciaban a emerger los nuevos líderes locales.

Simultáneamente, en diversas localidades mixtecas, mazatecas y triquis, entre otras, jóvenes con estudios universitarios, oriundos, empezaron a adherirse a $-\mathrm{y}$ a participar en- los movimientos locales que se oponían a las viejas prácticas caciquiles, al clientelazgo sindical y partidario, a la corporativización; que exigían del Estado programas sociales y de desarrollo, servicios públicos y eficiencia en la función pública, entre otros. Con mucha frecuencia, profesores y profesionistas coincidieron en el campo político, cada uno con su respectivo capital social (Bordieu, 1980). La 
presencia (simpatías, compromisos, etc.) lograda bien pronto les permitió modificar las reglas del juego: en diversas localidades, ambos grupos lograron modificar los mecanismos de participación política para insertarse en los gobiernos locales -en las instancias de gobierno municipal o, al menos, en el sistema de cargos- sin ser oriundos, y sin transitar por los escalafones internos de cargos, en algunos casos, a la vez que se defendía la propiedad comunal o ejidal (allí donde la había), los servicios colectivos en beneficio de la comunidad, la organización comunitaria para el ceremonial, la lengua y los usos y costumbres internos en general.

Intelectuales como Benjamín Maldonado, Jaime Díaz Luna, Adelfo Regino Montes y Floriberto Díaz hicieron ejercicios de síntesis de algunos elementos estructurales y estructurantes de la comunidad y propusieron el fortalecimiento, la recuperación o la adopción de la comunalidad como forma de vida y guía para el comportamiento social ${ }^{9}$. Profesores y profesionistas en las diversas regiones oaxaqueñas, en lo general, se adhirieron a la propuesta y la fortalecieron. Su capital social se incrementó. Más tarde, la necesidad de articular en un nivel superior todos los esfuerzos de la fracción de la CNTE y la marejada política de los pueblos oaxaqueños por democracia, justicia, mejores condiciones de vida y programas sociales, consolidaron la Asamblea Popular de los Pueblos de Oaxaca (APPO).

En este contexto, la APPO fue uno de los vehículos para la difusión de la comunalidad y, en muchos casos, la comunalidad fue hacia la Asamblea y la utilizó para su reproducción; como quiera que haya sido, ocurrió que profesionistas, profesores e intelectuales y activistas indígenas, produjeron en algunas localidades un cambio inusual: si los otrora cargos civiles dejaron de ser gratuitos y empezaron a ser servicios remunerados (puestos, como se afirma en Eloxochitlán de Flores Magón) ${ }^{10}$, y la lucha por acceder a ellos fragmentaba la estructura social y la política, cabía la posibilidad de decidir, desde dentro, alguna forma de resistencia: si el puesto era inevitable, lo que no lo era sería que el puesto fuese transformado en cargo ¿Cómo? Convirtiendo los salarios de los funcionarios remunerados en fondo ceremonial y de obra pública, como fue decidido en Santa María Tlahuitoltepec. Así, el puesto, transmutado en cargo conservaba, en tanto tal, su esencia (honorífico, gratuito y sometido al derecho comunitario) y se evitaba la confrontación que se presentó en otras localidades donde el cabildeo, la compra de voluntades (intenciones de voto) y la confrontación "ambiciosa" han fragmentado el tejido social (como ocurre en Santiago Yolomécatl, por citar un caso).

El caso de Tlahuitoltepec, basado en la interpretación local de la comunalidad y la forma de entender los cargos, desveló tres características del cargo y del sistema de cargos: la gratuidad, la perentoriedad y la normación de los cargos de acuerdo con reglas locales, como he insistido desde hace más de un lustro (Topete, 2010); asimismo, desveló el carácter honorífico del cargo (lo que se vincula con el reconocimiento más que con el prestigio). Ahora, estos rasgos dejan a descubierto la forma de hacer política: a diferencia del sistema de partidos para elección de puestos, en el que las organizaciones políticas invierten dinero (en buena medida extraído del IFE y, consecuentemente, del erario público) para posicionar implementadores de proyectos partidarios, para obtener fondos con los cuales posicionar a los propios partidos, y votantes para reproducir la estadía del partido en el poder, en la localidad se recupera la asamblea como instancia suprema de decisiones y las elecciones abiertas luego de intentonas consensuales en las que se privilegia la honorabilidad y capacidad para el servicio de tales o cuales miembros a ocupar cargos. En efecto, la citada transmutación ha puesto de relieve que la propia concepción del servicio público se sobrepuso a la legislación federal y de la entidad federativa, sin dejar de atenderlas; ha dejado a descubierto, además, que la constitución de autoridades compete exclusivamente a la localidad. Sin embargo, como ocurre en los estudios humanísticos, las variables psicosociales son más numerosas y menos controlables que las biológicas o las físicas.

En efecto, cierta indigenidad conservada, la presencia de la CNTE y de la APPO, no producen resultados homogéneos (de hecho, las variables sociales no generan efectos homogéneos). En contraste con el caso de Santa María Tlahuitoltepec, el posicionamiento que los profesionistas y los profesores lograron en Santiago Yolomécatl no desembocó en prácticas políticas similares: en esta localidad, si se reconoce la importancia de la religiosidad popular en diversos sistemas y estructuras, y se acepta que los puestos son remunerados, se lucha por controlar los espacios de autoridad pagados, pero desde allí se controlan -en una correlación diametralmente opuesta a la que existía antes- los cargos religiosos. ¿Cómo? Nombrando, desde el Honorable 
Ayuntamiento (puestos) los cargos que atenderán el servicio los santos; así se conserva el puesto y los cargos aunque no se conjura el conflicto que genera tal decisión, porque unos (puestos civiles, de administración) y otros (cargos para atender el ciclo ceremonial) son pensados por la población como servicios públicos.

Las vías opuestas de Yolomécatl y Tlahuitoltepec merecen una etnografía más específica y descriptiva, pero con lo que contamos se confirma que ciertas dosis de autonomía son saludables en el nivel comunitario; que la historia y la vía de los cargos no ha sido homogénea y que cualquier intento de universalización está condenada a corregirse (la realidad es más necia que la teoría, lo que le augura a esta un futuro azaroso). También fortalece la idea de que lo que hace al cargo ${ }^{11}$, aunque parezca un dislate, es que, más allá del ejercicio de voluntad autónoma o voluntad doblegada por las presiones sociales, es la carga su esencia: la gratuidad del servicio comunitario (sea a los santos ${ }^{12} \mathrm{o}$ a los asuntos civiles), por cierto incorporada en la propuesta de comunalidad; asimismo, lo que evita el desgaste de los servidores es la rotabilidad dispuesta en lo que le da sentido a cualquier cargo: las normas locales, las decisiones que la comunidad toma y defiende y que rigen el destino de los oficios diseñados para servir a los demás.

\section{Referencias Citadas}

Aguirre Beltrán, Gonzalo

1983 Formas de gobierno indígena, México, INI.

Bourdieu, Pierre

1980 "Le capital social-notes provisoires". en: Actes de Recherche en Sciences Sociales, $\mathrm{N}^{\circ} 31$, pp. 2-3.

Cámara Barbachano, Fernando

1996 "Organización religiosa y política en Mesoamérica", en L. Korsbaek, Introducción al sistema de cargos, Toluca, UAEM.

Cancian, Frank

1976 Economía y prestigio en una comunidad maya, México, INI.

Carrasco, Pedro

1990 "Sobre el origen histórico de la jerarquía políticoceremonial de las comunidades indígenas", en M. Suárez (coord., Historia, Antropología y política. Homenaje a Ángel Palerm (Vol. I), México, Alianza Editorial Mexicana.

Korsbaek, Leif

1996 Introducción al sistema de cargos, Toluca, UAEM.
Tax, Sol

1937 "The Municipios of the Midwestern Highlands of Guatemala", en American Anthropologist, New Series, Vol. 39, No $^{\circ}$, Part 1 (jul.-sep. 1937), pp. 423-444.

Topete Lara, Hilario

2005a "Cargos y otras yerbas", en Dimensión Antropológica, México, INAH-CONACULTA, N/E, Año 12, Vol. 33, eneroabril, 2005, ISSN-1405-776, pp. 91-115.

2005b "Variaciones del sistema de cargos y la organización comunitaria para el ceremonial en la etnorregión purépecha", en Cuicuilco, México, INAH-CONACULTA, N/E, Vol. 12, $\mathrm{N}^{\circ} 34$, mayo-agosto de 2005, pp. 95-129.

2010 "Los lugares comunes y los vacíos en los estudios sobre los sistemas de cargos religiosos", en Argumentos, Estudios críticos de la sociedad, México, Nueva Época, Año 23, № 62, enero-abril de 2010, pp. 281-303.

Wolf, Eric

1981 "Comunidades corporativas cerradas de campesinos en Mesoamérica y Java Central”, en J. R. Llobera (comp.) Antropología económica. Estudios etnográficos, Barcelona, Anagrama.

\section{Notas}

1 El servicio a los santos es, en cierta forma, un servicio a la comunidad. Las peticiones de lluvia, trabajo, buenas cosechas; la provisión de alimentos, bebidas, música, oficios religiosos, castillos y otros, siempre se brindan a los demás. Esto no descarta los proyectos personales: restaurar el honor por la palabra (promesa) empeñada; reciprocar al santo por un favor recibido (vida, salud, fortuna) o solicitado para sí o para otros; obtención de prestigio o reconocimiento al menos; y, entre otros, canjear el capital social obtenido mediante el cumplimiento del cargo por capital político.

2 Por razones elementales, un cargo no hace un sistema. Para que exista un sistema de cargos se requiere al menos de dos cargos articulados entre sí.

3 Proponía que los sistemas de cargos podían ser del tipo cívico-religioso o político-religioso, sin embargo, la desarticulación evidente que ha producido el avance de la municipalización bien podría no afectar el sistema de cargos religiosos. De hecho, los sistemas de cargos que más conocemos son de este tipo, y solo algunos son escalafonarios; de los sistemas de cargos religiosos, agregaba, no todos son jerarquizados.

4 La comprensión de un concepto, en su acepción más formal, es el conjunto de notas inteligibles del mismo; en cambio, la extensión la constituye el conjunto de individuos (seres individuales) a los que se predica el concepto.

5 Estas ideas las había pergeñado, además, en "Los lugares comunes y los vacíos en los estudios sobre los sistemas de cargos religiosos" (Topete, 2010), que puede considerarse como la antesala del presente ensayo.

6 "Ayudar a alguien a condición de reciprocidad". 
7 PROCAMPO (Programa de Apoyos Directos al Campo) es un programa del gobierno federal que consiste en subsidios en dinero efectivo por hectárea cultivada (produzca o no) o en producción (simulada o real) pecuaria. Inició en 1993 y ha sido una de las razones de la distorsión productiva y económica en el campo toda vez que el apoyo pecuniario no se proporciona por producción ni productividad, sino por superficie registrada. Las consecuencias de esta política, entre otras, han sido la deforestación, el clientelaje, la cooptación electoral, etcétera.

8 PROCEDE (Programa de Certificación de Derechos Ejidales y Titulación de Solares Urbanos) es un programa del gobierno federal que pretende dar certidumbre en materia de tenencia de la tierra y la posibilidad de decidir el uso y destino de los derechos sobre ella mediante la extensión de certificados de derechos. Independientemente de la modalidad de propiedad y tenencia, el PROCEDE, nacido en 1992, se encarga de certificar a título personal el predio sometido a usufructo, independientemente de su estatus ejidal o comunal. Una de las consecuencias de su aplicación ha sido la creación de la ficción de que los usufructuarios o comodatarios son propietarios que pueden vender sus derechos sobre la tierra con la consecuente compra por otros, lo que ha generado gradualmente grandes concentraciones de tierra en unas cuantas manos: neolatifundismo, pues, de un lado; de otro, la pérdida de derechos que anteriormente preservaba el espíritu de la Constitución Política de los Estados Unidos Mexicanos.

9 Benjamín Maldonado sostiene que la comunalidad tiene cuatro elementos centrales: territorio (defensa, propiedad y tenencia de la tierra), trabajo (tequios, ayudas mutuas), poder (fundamentalmente cargos en el gobierno local) y fiesta (religiosa o cívica), sujetos constantemente a intersecciones con elementos culturales como la lengua, cosmovisión, religiosidad y, entre otros, conocimientos. La comunalidad es la condición sine qua non de la comunidad indígena. Adelfo Regino Montes, Jaime Díaz Luna y Floriberto Díaz coinciden casi plenamente con las ideas de Maldonado.

10 El testimonio fue proporcionado verbalmente por Alberto Rosete Cabanzo, mazateco de Eloxochitán de Flores Magón.

11 Un cargo no hace un sistema de cargos: el primero puede existir sin el segundo, como lo prueba la existencia de mayordomías de Santo Patrono allí donde solo se ha conservado una fiesta religiosa; por ello mismo, no le es inherente un escalafón ni una jerarquía, aunque puede estar dentro del uno, de la otra o entre ambos. Puede articularse si es civil, con uno o más religiosos o si es religioso, con uno o más civiles (agrarios incluidos), pero no le es necesaria la articulación y menos el sistema de cargos alternos (entre lo civil y lo religioso) y escalafonarios. Por último, es claro que el cargo al ser civil o religioso puede ser independiente y estar sometido a un escalafón o jerarquía sin que ello sea condición generalmente aceptada para transitar de un ámbito al otro. Esto no anula la posibilidad de que al realizar un servicio religioso se logre un considerable capital social para canjearlo por votos o simpatías en eventos ulteriores. 12 El servicio a los santos es, de hecho, un servicio a la colectividad. Cuando se realiza una fiesta patronal, de barrio o de mitad, se garantiza -o al menos se propicia- el derramamiento de dones sobre todos y no exclusivamente sobre el carguero. Esta dimensión se hace más evidente cuando se pide lluvia o buenas cosechas. 